\title{
The Influence of Demographic Variables on Environmental Consciousness of the Low Income Communities
}

\author{
M. S. Barliana, U. Surahman \\ Department of Architectural Education \\ Universitas Pendidikan Indonesia \\ Bandung, Indonesia \\ aombarli@upi.edu
}

\author{
T. Kubota \\ Hiroshima University \\ Japan
}

\begin{abstract}
The global society currently faces problems and constraints in energy saving measures, one of which is a lack of environmental awareness. Therefore, prior to entering the technical problems of energy saving as part of sustainable architecture, it is required to raise public awareness to be more sensitive to the environment. After awareness was raised, then they will be able to apply the cultural attitudes and behaviors that support sustainable architecture. Hence, as a first step, this study is intended to study the awareness level of urban communities in Indonesia and investigate the external variables (demographic) which influence it dominantly. These demographic variables include gender, education, income, marriage, employment, health, religiosity, leisure, competence, culture/ethnic, and social life. This pilot research is using a combination of quantitative and qualitative methods. Quantitative methods are used as the primary method of research, while qualitative methods is used to support it. The research was conducted at lower class residential area in Bandung. The results of the pilot survey showed that education, religion, social meeting, and public spaces variables had high positive correlation, and significant to the environmental consciousness. However, further research could explore the external side of education or religious aspect, such as the influence of training in non formal education, community empowerment, religious leaders, community leaders, and other communication media, which can provide environmental knowledge and environmental concern.
\end{abstract}

Keywords- Sustainable architecture, energy saving, demographic variables, environmental consciousness, environmental knowledge, environmental awareness.

\section{INTRODUCTION}

It raises a variety of attempts to produce appropriate solutions for environmental problems. Therefore by designing a built environment, one of the problem solving concept is "sustainable architecture". Sustainable architecture, is an architecture that meets current needs, without compromising the ability of future generations to meet their own needs[1]. The needs are differ from one to another society, from one to another region and determined by the relevant community is the best way.
However, sustainable architecture is not a panacea recipe that can easily solve environmental problems. Sustainable architecture is also not just a technology issue-related material, including through more efficient energy use, efficiency of land use, materials use, use of technology and new materials, and waste management. Sustainable architecture is about cultural attitudes."Sustainable architecture isn't a prescription. It's an approach, an attitude. It should not really even have a label. It should be architecture" [2].

This study focuses on the behavior of the energy savings as part of the cultural attitudes that support sustainable architecture. Regarding to the behavior of energy-saving culture, one very important factor to consider is the environmental awareness or environmental consciousness. Showing the 13 constraints in energy saving measures, one of them is a lack of environmental awareness [3].

In Indonesia, when technical sustainable architecture solutions with the logic of rational-efficiency have not been understood yet, and when the wisdom traditions are abandoned, it is important to examine attitudes and cultural behaviours of the latest urban communities. Indeed, it involves the low-middle class, who inhabit the low-income housing and slum housing. For them, which are generally less educated, technical knowledge on sustainable architecture, especially energy saving, course is very important. However, efforts of technical knowledge transfer will face two problems. First, education and socialization is very difficult because of socio-economic pressures, the concept of sustainable architecture would be considered a luxury. Second, after the knowledge gained, the next challenge is how this knowledge is implemented well by them. This implementation, in addition is to address the issue of socio-economic pressures, as well as issues of cultural attitudes and behavior.

In consequence, prior to admission to the technical issues of sustainable architecture especially energy it is required first to awaken their consciousness to be more sensitive to the environment. After consciousness was raised, then they will be able to apply the cultural attitudes and behaviours that support sustainable architecture. 
Hence, as a first step, this study wanted to study how far the awareness level of urban communities in Indonesia, especially in low-income communities, and what the external variables (demographic) which influence dominantly. Demographic variables or personal variables, these characteristics look at how the population is changing based on individual factors such as: gender, education, income, marriage status, employment, health, religiosity, leisure, competence, culture/ethnic, and social life.

Demographic variables concept was adapted from the theory of the factors that influence the happiness life. In detail, the following is presented a number of factors that affect a person's happiness [4][5]. The demographic and environmental variables consisting of: (1) Sex (2) Education, (3) Revenue, (4) Marriage, (5) Occupation, (6) Health, (7) Religiosity; (8) Leisure time; (9) Competence; (10) Culture/Ethnicity: (11) Social life.

Meanwhile, many difficulties need to be dealt with to meet the expected aim of social development, especially is energy saving effort. There are many barriers that should be removed. Review of literatures on energy saving and opinion of experts from energy industry and academia, 13 barriers to energy saving were put forward [3]. The literature review as well as the experts opinion was used to develop the relation matrix, which was later applied in the ISM model. These barriers are lack of awareness of energy saving (LA), lack of experience in technology and management (LETM), lack of funding or financing difficulties (LFFDs), limited policy framework (LPF), lack of research personnel or trained manpower (LRTP), lack of public participation (LPP), inadequate data and information (IDI), reluctance to invest because of high investment risk (RI), objections from the vested interests groups (OVIG), inappropriate industrial framework (IIF), lack of strategic planning (LSP), lack of appropriate production technologies (LAPT) and lack of incentive support (LIS).

One of the main causes of the difficulties in saving energy is the lack of environmental consciousness and responsibility. Therefore, it is very important to explore this issue [3].

In the analysis of environmental psychology, there are so many terms and definitions of the attitudes and environmental behavior, including awareness, commitment, consciousness, awareness, responsibility, behavior, action, etc., in the sense that different. In this study, we took a simple sense, includes all those things, except behavior or environmental caution. Thus, the sense of awareness, commitment, and responsibility, is considered covered by the definition of consciousness.

The environmental responsibility as follows: individual shows sense of responsibility and moral sense adopting certain environmental behavior for the environmental problems or to solve it [6]. Environmental responsibility as an individual's sense of responsibility and moral in the prevention of environmental degradation or the solution of specific environment problems and the one is willing to take positive environment behavior [7].
Meanwhile, models of the factors that research suggests are related to environmental concern. Such models make a distinction between cognitive variables or the levels of understanding of environmental issues and how to take action [6]; psycho-social variables that include attitude towards environmental issues; locus of control or feelings of efficacy capacity to bring about change; and sense of responsibility to do something to reduce environmental degradation;

By adopting the model, then environmental conscsiousness term in this research includes only cognitive variables or the levels of understanding of environmental issues and how to take action and part of psycho-social variables that include attitude towards environmental issues and sense of responsibility to do something to reduce environmental degradation.

In line with that, Environmental consciousness consisting of environmental knowledge and environmental concern [6]. In young people context, they stated that environmental consciousness consisting of people who are minimizing their environmental impact, reducing consumption and reusing and recycling materials. These include their expressed willingness to adopt measures like energy saving or toallocate resources for conservation, the position they place the environment concerns or values, their expressed willingness to fore go consumption and accept government regulation for environmental preservation, and finally, the extent to which they show concern for all life and not simply that of humans.

\section{RESEARCH METHOD}

This research is using a combination of quantitative and qualitative methods. It specifically mentioned by Creswell (1994) as a dominant-less dominant design. Quantitative methods are used as the primary method of research, while qualitative methods only to support.

The research was conducted in a low class residential area in Bandung which is representation the vernacular housing of settlements in urban areas. The respondents of this study were residents of such housing, which serve as the leaders of the family (husband and/or wife).

TABLE I. DATA ANALYSIS TECHNIQUES

\begin{tabular}{|c|c|c|c|}
\hline No. & Analysis Technique & SpectrumStudy & Criterium \\
\hline 1. & $\begin{array}{l}\text { Descriptive : Mean, } \\
\text { and Trend T est }\end{array}$ & $\begin{array}{l}\text { Enviromental } \\
\text { Consciouness }\end{array}$ & See. Table 2 \\
\hline 2. & Correlation Analysis & $\begin{array}{c}\text { Relation between } \\
\text { Demographic } \\
\text { Variables with } \\
\text { Enviromental } \\
\text { Consciousness }\end{array}$ & $\begin{array}{c}\text { Parametric } \\
\text { Statistical } \\
\text { (Pearson } \\
\text { product } \\
\text { moment) cause } \\
\text { eligble for } \\
\text { nornality and } \\
\text { Homogenity } \\
\text { Testing } \\
\end{array}$ \\
\hline
\end{tabular}


Selection criteria of the residents respondents was based on three things, namely the large $(<50 \mathrm{~m} 2)$, structure of the home building (impermanent, semi-permanent) and income levels (< $\$ 200$ ) of respondents. Based on these parameters, this pilot survey covered only a small sample (25 respondents) which were selected by systematic sampling purposive approach. The number of questioner returned and processed is 16 respondents. The site of lower class is set purposively, Cihampelas at Coblong District and Sarikaso at Sukasari District, Bandung, West Java, which includes dense urban village areas

The main data collection techniques used questionnaires, and supported by observations, interviews, and documentation of study. This study used two measurement instruments to assess demography variables and energy saving consciousness. The instrument to measure Environmental Consciousness of Energy Savings will use questioner [6]. Variable of enviromental consciousness consist of environment knowledge and environmental concern.

The entire processing of quantitative data used SPSS computer program, and was analyzed by qualitative way through the confirmation to the relevant theory.

Descriptive Interpretation Criteria. Describing the Demographic Variables and Environmental Consciousness used descriptive analysis, with showing the data frequency, means, modes, and the median. The next test performed is a tendency to interpret the data.

TABLE II. MEASUREMENT CRITERIA OF DESCRIPTIVE INTERPRETATION

\begin{tabular}{|c|c|}
\hline Criteria & Conclusion \\
\hline $\mathrm{M}^{1}=\mathrm{P}^{2}+1.5 \mathrm{SD}$ up & Very strong/very high \\
\hline $\mathrm{M}=\mathrm{P}+0.5 \mathrm{SD}$ to $\mathrm{P}+1.49 \mathrm{SD}$ & Strong/High \\
\hline $\mathrm{M}=\mathrm{P}-0.49 \mathrm{SD}$ to $\mathrm{P}+0.49 \mathrm{SD}$ & Quite strong/quitehigh \\
\hline $\mathrm{M}=\mathrm{P}-1.49 \mathrm{SD}$ to $\mathrm{P}-0.50 \mathrm{SD}$ & Weak/Low \\
\hline $\mathrm{M}=\mathrm{P}-1.5 \mathrm{SD}$ down & Very Weak/Very low \\
\hline
\end{tabular}

${ }^{1} \mathrm{M}=$ Mean

Interpretation data through trend test based on the means of each variable are compared with certain parameters. This parameter is determined based on the consideration of researchers with reference to the concept of judgment theory. This parameter is set $75 \%$ of the average product of the maximum score (5) on option of the instrument response with the number of items and questions with scale interval (100) for the ratio scale, so that the parameters are 3.75 and 75 . The maximum score is not used as a parameter, with the consideration that ideal condition possible theoretically, and almost impossible happen in the reality life. Interpretation of these criteria, formulated as follows table 2:

Interpretation of Correlational Criteria. To see the strong or weak relation between variables, based on the following parameters:

$$
0-0.25
$$

very weak correlation
$>0.25-0.5$
$>0.5-0.75$
strong enough correlation
$>0.75-1$
strong correlation
very strong correlation

To find out whether the correlation numbers is significant or not, then the hypothesis was tested, with the parameters $5 \%$ significance level $(\alpha=0.05)$. If the probability $<0.05$, it means a significant relation between the two variables. Otherwise, if the probability is $>0.05$, then the relations between the two variables is insignificant.

Testing requirements of parametric statistical analysis included tests of normality and homogeneity. The data show that all eligible. The data were normal distributions because all variables have Asymp. Sig coefficient > 5\% alpha and Homogenity population because all variables have Asymp. Sig coefficient $>5 \%$ alpha. Thus, data processing can be continued by using parametric statistics.

\section{RESEARCH FINDINGS AND DISCUSSION}

In accordance with the problem, this research examines the influence of Demographic Variable Environmental Consciousness, using statistical techniques Factor Analysis and Regression Linear or Path Analysis. However, after testing the requirements of linear regression, the data apparently did not qualify. It happens because the pilot survey had a small number of samples (below 30 respondents), so the variance is also limited. In addition, sampling was not done randomly. Therefore, the data processing is only done through descriptive analysis and correlation analysis using Pearson Product Moment.

In table 3, shown the results of data processing to see the average (mean) of the variables studied, compared with the interpretation criteria based trend test, as described in the research methods.

TABLE III. DESCRIPTIVE ANALYSIS RESULT OF LEVEL ENVIRONMENTAL CONSCIOUSNESS

\begin{tabular}{|r|l|r|r|r|r|l|l|}
\hline No & \multicolumn{1}{|c|}{ Variable } & N & Mean & $\begin{array}{c}\text { Std. } \\
\text { Deviation }\end{array}$ & Parameter & Suitable to criterium & Conclusions \\
\hline 1 & $\begin{array}{l}\text { Environmental } \\
\text { Knowledge }\end{array}$ & 16 & 49.9800 & 14.90116 & 75 & M = P - 1.5 SD down & $\begin{array}{l}\text { Very Weak/ } \\
\text { Very low }\end{array}$ \\
\hline 2 & $\begin{array}{l}\text { Environmental } \\
\text { Concern }\end{array}$ & 16 & 11.4375 & 1.09354 & 15 & M = P - 1.5 SD down & $\begin{array}{l}\text { Very Weak/ } \\
\text { Very low }\end{array}$ \\
\hline 3 & $\begin{array}{l}\text { Environmental } \\
\text { Consiousness }\end{array}$ & 16 & 61.8550 & 14.55852 & 90 & M = P - 1.5 SD down & $\begin{array}{l}\text { Very Weak/ } \\
\text { Very low }\end{array}$ \\
\hline
\end{tabular}

Environmental variables consciousness is a combination of environmental knowledge and environmental concern. Environmental variables including categories of knowledge is very low, and very low environmental concern. When measurements are combined into environmental consciousness, the category is very low. It means among the very poor respondents shave knowledge of the environment and do not care about the environment. It is a worrying fact.

Referring to bivariate correlation data analysis in Table 4, the results can be interpreted as follows. Judging from the amount of correlation value, most of the relationship between variables that are in the category of very weak or no relationship and strong category. There are only two 
relationships between variables, which have a strong relationship with the categories, namely variable correlation with environmental education and environmental concern and consiousness (positive relationship), as well as public space with environmental concern. Furthermore, there is no relationship between the variables that are in a very strong category.

Based on the findings, then education must be a priority development programs to improve the environmental consciousness of the lower class. Education is in various forms of informal training, community empowerment, and education through various media channels. It is include the exchange of information in a social gathering and interaction of residents in public spaces.

This was reinforced by the results of hypothesis testing. By looking at the values of significance compared to the confidence level $\alpha=0.05$, it can be concluded that the relationship between variables which have a positive and significant correlation, is to reject Ho and accept Ha, are: (1) the relationship between the variables education with environmental concern $(0558<\alpha=0.05)$ as well as environmental consciousness $(0580<\alpha=0.05)$, (2) the relationship between the religious with the environmental consciousness $(0499<\alpha=0.05)$, (3) social relations meeting with environmental consciousness $(0499<\alpha=0.05)$, (4) relationship with public space environmental concern (0558 $<<\alpha=0.05)$.

Based on the results of testing this hypothesis, factors besides education, public space, and social meetings, the factors religiousity should be explored further. Increased environmental consciousness must involve the influence of religious leaders and informal leaders to be role models, for example.

TABLE IV. RESULT OF CORELATIONAL ANALYSIS

\begin{tabular}{|c|c|c|c|c|c|}
\hline No & Variable & & $\begin{array}{c}\text { Environmental } \\
\text { Knowledge }\end{array}$ & $\begin{array}{c}\text { Environmental } \\
\text { Concern }\end{array}$ & $\begin{array}{c}\text { Environmental } \\
\text { Consiousness }\end{array}$ \\
\hline \multirow[b]{3}{*}{1} & \multirow[t]{3}{*}{ Education } & Pearson Correlation & .462 & $.558^{\circ}$ & $.580^{\prime \prime}$ \\
\hline & & Sig. (2-tailed) & .071 & .025 & .019 \\
\hline & & $\mathbf{N}$ & 16 & 16 & 16 \\
\hline \multirow[b]{3}{*}{2} & \multirow[t]{3}{*}{ Satisfaction } & Pearson Correlation & .295 & .003 & .194 \\
\hline & & Sig. (2-tailed) & .267 & .991 & .472 \\
\hline & & $\mathbf{N}$ & 16 & 16 & 16 \\
\hline \multirow[b]{3}{*}{3} & \multirow[t]{3}{*}{ Religion } & Pearson Correlation & .497 & .462 & $.499 "$ \\
\hline & & Sig. (2-tailed) & .050 & .071 & .049 \\
\hline & & $\mathbf{N}$ & 16 & 16 & 16 \\
\hline \multirow[b]{3}{*}{4} & \multirow[t]{3}{*}{ Income } & Pearson Correlation & .218 & .290 & .233 \\
\hline & & Sig. (2-tailed) & .417 & .276 & .384 \\
\hline & & $\mathbf{N}$ & 16 & 16 & 16 \\
\hline \multirow[b]{3}{*}{5} & \multirow[t]{3}{*}{ Sufficiency } & Pearson Correlation & .194 & .185 & .166 \\
\hline & & Sig. (2-tailed) & .472 & .493 & .538 \\
\hline & & $\mathbf{N}$ & 16 & 16 & 16 \\
\hline \multirow[b]{3}{*}{6} & \multirow[t]{3}{*}{ Job } & Pearson Correlation & -.099 & .462 & .010 \\
\hline & & Sig. (2-tailed) & .714 & .071 & .969 \\
\hline & & $\mathbf{N}$ & 16 & 16 & 16 \\
\hline \multirow[b]{3}{*}{7} & \multirow{3}{*}{$\begin{array}{l}\text { Environment } \\
\text { security }\end{array}$} & \begin{tabular}{|l|} 
Pearson Correlation \\
\end{tabular} & .084 & -.095 & -.057 \\
\hline & & Sig. (2-tailed) & .756 & .727 & .833 \\
\hline & & $\mathbf{N}$ & 16 & 16 & 16 \\
\hline \multirow[b]{3}{*}{8} & \multirow[t]{3}{*}{ Trip security } & Pearson Correlation & .073 & -.424 & -.056 \\
\hline & & Sig. (2-tailed) & .789 & .102 & .836 \\
\hline & & $\mathbf{N}$ & 16 & 16 & 16 \\
\hline \multirow[b]{3}{*}{9} & \multirow[t]{3}{*}{ Healthy } & \begin{tabular}{|l|} 
Pearson Correlation \\
\end{tabular} & .323 & .185 & .215 \\
\hline & & Sig. (2-tailed) & .223 & .493 & .423 \\
\hline & & $\mathbf{N}$ & 16 & 16 & 16 \\
\hline & \multirow[t]{3}{*}{ Desease } & Pearson Correlation & .362 & .359 & .340 \\
\hline & & Sig. (2-tailed) & .169 & .173 & .198 \\
\hline 10 & & $\bar{N}$ & 16 & 16 & 16 \\
\hline
\end{tabular}

\section{CONCLUSION}

Referring to the results of the studies mentioned above, some conclusions can be formulated as follows :

- Citizens under the very lack of environmental knowledge and do not care about the environment. This is shown by the fact that the level of environmental knowledge and environmental concern is very low, so in general the degree of environmental consciousness is verylow.

- Education variable as a strong relationship with the categories of environmental concern and environmental consiousness. Variable of public space has a strong relationship with environmental concern.

- There is a positive and significant relationship: between the variables education with environmental concern, and environmental consciousness; between religious with environmental consciousness; between social meetings with environmental consciousness; between public space with environmental concern.

\section{LIMIT ATIONSOF PILOT SURVEYS}

- The results of the research through pilot surveys certainly not describe the results of in-depth research and comprehensive. Pilot surveys with small samples, and the sampling technique was not through random sampling, resulting in a quantitative approach with robust statistical methods cannot be applied.

- On the otherhand, because of time constraints and field workers who have not received training intensive, the exploratory interviews that are more naturalistic and participative cannot be applied. Though the lower classes respondent, who are generally less educated, the data collection approach is more suitable to be applied. This approach will be more revealing than the reality and significance of quantitative statements are difficult to express by the lower classes.

\section{ACKNOWLEDGMENT}

Thanks to all those who have contributed to this research, especially for International Development and Cooperation (IDEC), Hiroshima University, and Japan Society for Promotion of Science (JSPS) as a funds research sponsor. We also convey appreciation to the residents respondents of Cihampelas at Coblong District and Sarikaso at Sukasari District, Bandung, West Java, which has become the subject of this study.

\section{REFERENCES}

[1] Steele, James (1997). Sustainable Architecture; Principles, Paradigms, and Case Studies. New York: McGraw-Hill

[2] Guy, Simon and Farmer, Francis (2001). Reinterpreting Sustainable Architecture: The Place of Technology," Journal of Architectural Education, vol. 54, no. 3 (Feb. 2001)

[3] Wang, Guo Hong., Wang, Yun Xia.,Zhaoa, Tao. (2008). Analysis of interactions among the barriers to energy saving in China Energy Policy 36. 1879-1889 
[4] Carr, A. (2004). Positive psychology: The science of happiness and human strengths. New York: Brunner-Routledge.

[5] Eddington, N. \& Shuman, R. (2005). Subjective well-being (happiness). Avaliable at: http://www.texcpe.com/cpe/PDF/

[6] Hines J. M., Hungerford H. R., Tomera A. N. (1986). Analysis and synthesis of research on responsible environmental behavior: A metaanalysis. The Journal of Environmental Education., 18(2):1-8.

[7] Wenshun, Wang. , Xiaohua, Li., Hualong, Li. (2010). Empirical Research of theEnvironmental Responsibility Affected on the Urban Residential Housing Energy Saving Investment Behavior. IACEED2010. Energy Procedia 5 (2011)991-997 